\title{
Solução de crimes ambientais pelo Poder Judiciário na Amazônia legal: a utilização da perícia ambiental
}

\author{
Solving environmental crimes by the Judiciary in the legal Amazon: the use of environmental \\ expertise
}

Solución de delitos ambientales por parte del Poder Judicial en la Amazonia jurídica: el uso de la experiencia ambiental

\author{
Maria do Socorro Soares Cunha \\ ORCID: https://orcid.org/0000-0002-5199-5058 \\ Universidade Federal do Sul e Sudeste do Pará, Brasil \\ E-mail: socorro_cunha@unifesspa.edu.br \\ Danilo Elias de Oliveira \\ ORCID: https://orcid.org/0000-0003-1428-6444 \\ Universidade Federal do Sul e Sudeste do Pará, Brasil \\ E-mail: deoliveira@unifesspa.edu.br
}

\begin{abstract}
Resumo
A solução de crimes ambientais, no âmbito de processos judiciais tramitados no Poder Judiciário, muitas das vezes, demanda a necessidade de intervenção de variados campos do conhecimento, entre eles, cita-se a perícia ambiental. Essa modalidade de perícia consiste em um meio de produção de provas capaz de desvendar a extensão do dano ambiental ao meio ambiente e, por consequência, estimar a reparação devida, seja na forma de indenização ou obrigação de fazer. Para além disso, a perícia ambiental subsidia o julgador de conhecimentos específicos que fogem de sua formação acadêmica, auxiliando-o até mesmo na fundamentação da sentença que será proferida. Assim, levando em consideração que a Constituição de 1988, na norma agasalhada no art. 225, assegura que todos têm direito ao meio ambiente ecologicamente equilibrado, bem de uso comum do povo e essencial à sadia qualidade de vida, impondo-se ao Poder Público e à coletividade o dever de defendê-lo e preservá-lo para as presentes e futuras gerações, o combate aos crimes ambientais é um dever do Estado, e para tanto, a perícia ambiental representa uma grande aliada da solução de crimes que viola o meio ambiente (bem ambiental). Isso posto, dada a sua importância, o presente artigo tem como fito apresentar de que modo a perícia ambiental vem contribuindo no Poder Judiciário para solucionar os crimes ambientais, sobretudo na região da Amazônia Legal. O percurso metodológico a ser realizado é o da pesquisa bibliográfica e documental, com consulta a livros, periódicos, artigos, dissertações e diplomas normativos relacionados com o tema.
\end{abstract}

Palavras-chave: Crimes ambientais; Perícia ambiental; Poder judiciário.

\begin{abstract}
The solution of environmental crimes, within the scope of legal proceedings processed by the Judiciary, often requires the need for intervention from various fields of knowledge, including environmental expertise. This type of expertise consists of a means of producing evidence capable of unraveling the extent of the environmental damage to the environment and, consequently, estimating the necessary repair, either in the form of indemnity or obligation to do so. In addition, the environmental expertise subsidizes the judge with specific knowledge that is beyond their academic training, even helping them to substantiate the judgment that will be handed down. Thus, taking into account that the 1988 Constitution, in the rule enshrined in art. 225, ensures that everyone has the right to an ecologically balanced environment, a good for common use by the people and essential to a healthy quality of life, imposing on the Public Power and the community the duty to defend and preserve it for the present and For future generations, combating environmental crimes is a duty of the State, and for that, environmental expertise represents a great ally in solving crimes that violate the environment (environmental good). That said, given its importance, this article aims to present how environmental expertise has contributed in the Judiciary Power to solve environmental crimes, especially in the Legal Amazon region. The methodological path to be followed is that of bibliographical and documental research, with consultation of books, periodicals, articles, dissertations and normative diplomas related to the subject.
\end{abstract}

Keywords: Environmental crimes; Environmental expertise; Judicial power. 


\begin{abstract}
Resumen
La solución de los delitos ambientales, en el ámbito de los procesos judiciales tramitados por el Poder Judicial, a menudo requiere la intervención de diversos campos del conocimiento, incluida la pericia ambiental. Este tipo de pericia consiste en un medio de producir evidencia capaz de desentrañar la magnitud del daño ambiental al medio ambiente $\mathrm{y}$, en consecuencia, estimar la reparación necesaria, ya sea en forma de compensación u obligación de hacerlo. Además, la pericia ambiental subvenciona al juez con conocimientos específicos que van más allá de su formación académica, ayudándole incluso a fundamentar la sentencia que se dictará. Así, teniendo en cuenta que la Constitución de 1988, en la norma consagrada en el art. 225, asegura que toda persona tiene derecho a un medio ambiente ecológicamente equilibrado, bien de uso común de las personas y esencial para una calidad de vida saludable, imponiendo al Poder Público y a la comunidad el deber de defenderlo y preservarlo para el presente y Para las generaciones futuras, combatir los delitos ambientales es un deber del Estado, y para ello, la pericia ambiental representa un gran aliado en la resolución de delitos que atentan contra el medio ambiente (bien ambiental). Dicho esto, dada su importancia, este artículo tiene como objetivo presentar cómo la pericia ambiental ha contribuido en el Poder Judicial para resolver los delitos ambientales, especialmente en la región de la Amazonia Legal. El camino metodológico a seguir es el de la investigación bibliográfica y documental, con consulta de libros, revistas, artículos, disertaciones y diplomas normativos relacionados con la asignatura.
\end{abstract}

Palabras clave: Delitos ambientales; Experiencia medioambiental; Poder judicial.

\title{
1. Introdução
}

O desmatamento ilegal na floresta Amazônica é uma prática constante. Segundo dados recentes publicados pelo Instituto do Homem e Meio Ambiente da Amazônia [Imazon] (2021), instituição brasileira de pesquisa que tem como missão promover conservação e desenvolvimento sustentável na Amazônia, o desmatamento na Amazônia cresceu $30 \%$ no ano de 2020 em comparação com o ano de 2019, batendo recorde dos últimos 10 anos. Entre janeiro e dezembro de 2020, de acordo com o Imazon, a floresta Amazônica perdeu $8.058 \mathrm{~km}^{2}$ de área verde.

Diante desses dados alarmantes, a persecução do crime ambiental de desmatamento ilegal se faz necessário e, para que isto ocorra, a utilização da perícia ambiental é capaz de subsidiar às demandas judiciais para o esclarecimento dos fatos em apreciação. Para além disso, se faz necessária a formação de profissionais especializados (peritos) capazes de atender às necessidades do Poder Judiciário para clarear a elucidação dos fatos de acordo com as exigências existentes nos crimes de desmatamento ilegal na floresta Amazônica, notadamente, na região da Amazônia Legal que compreende, segundo a lei complementar n⿳ 124, de 3 de janeiro de 2007, os Estados do Acre, Amapá, Amazonas, Mato Grosso, Rondônia, Roraima, Tocantins, Pará e do Maranhão na sua porção a oeste do Meridiano 44º

A perícia ambiental constitui como um meio de prova, produzido por um profissional técnico com formação especializada na área, que auxiliará o magistrado em compreender à dinâmica dos fatos a ser objeto de apreciação. A atuação do perito ambiental está prevista na norma agasalhada no art. 149 do Código de Processo Civil (CPC), considerado como um dos auxiliares da justiça. Logo, a solução de crimes ambientais pelo Poder Judiciário com jurisdição na Amazônia Legal requer, muita das vezes, o auxílio de perícias ambientais realizadas por peritos especializados. Desta feita, dada a sua importância, o presente escrito tem por finalidade apontar os motivos que justificam a necessidade e a relevância da perícia ambiental no bojo de processos judiciais que apreciam os crimes ambientais ocorridos na Amazônia Legal.

\section{Metodologia}

O percurso metodológico empregado foi o da pesquisa bibliográfica - elaborada a partir de material já publicado, constituído principalmente de: livros, revistas, publicações em periódicos e artigos científicos, jornais, boletins, monografias, dissertações, teses, material cartográfico e internet (em especial, a literatura de Josimar Ribeiro de Almeida, Ângelo de Sá Mazzarotto e Marcelo Schmid) -, e da pesquisa documental - baseado em materiais que não receberam ainda um tratamento analítico ou que podem ser reelaborados de acordo com os objetivos da pesquisa, tais como diplomas normativos relacionados com o tema (Constituição da República Federativa do Brasil de 1988, Resolução nº 1, de 23 de janeiro de 1986 do Conselho 
Nacional do Meio Ambiente e Código de Processo Civil) (Prodanov \& Freitas, 2013).

Com relação ao espaço geográfico de observação, optou-se por analisar o número de processos judiciais que tramitam nos Tribunais brasileiros com jurisdição na região da Amazônia Legal que compreende, segundo a lei complementar ${ }^{\circ}$ 124, de 3 de janeiro de 2007, os Estados do Acre, Amapá, Amazonas, Mato Grosso, Rondônia, Roraima, Tocantins, Pará e do Maranhão na sua porção a oeste do Meridiano $44^{\circ}$. A escolha por este espaço de observação se justifica pelo elevado índice de crimes ambientais decorrentes de violação ao meio ambiente.

\section{Resultados e Discussão}

De acordo com a Constituição da República Federativa do Brasil de 1988 (CRFB/88), todos têm direito ao meio ambiente ecologicamente equilibrado, bem de uso comum do povo e essencial à sadia qualidade de vida, impondo-se ao Poder Público e à coletividade o dever de defendê-lo e preservá-lo para as presentes e futuras gerações (BRASIL, 1988). Em complemento, a Política Nacional do Meio Ambiente (PNMA), introduzido no ordenamento jurídico pátrio pela lei $\mathrm{n}^{\circ}$ 6.938, de agosto de 1981, define meio ambiente como o conjunto de condições, leis, influências e interações de ordem física, química e biológica, que permite, abriga e rege a vida em todas as suas formas (Brasil, 1981). Assim, diante da importância deste bem jurídico, o meio ambiente acaba por receber especial proteção.

Pelos ensinamentos da notável doutrina de Celso Antônio Pacheco Fiorillo (2013), compreende-se que o meio ambiente, ao analisar a sua natureza jurídica, não se confunde como bem público, nem mesmo como bem privado. Para o autor, o meio ambiente possui uma natureza jurídica única: bem ambiental.

O bem ambiental, fundamental, como declara a Carta Constitucional, e porquanto vinculado a aspectos de evidente importância à vida, merece tutela tanto do Poder Público como de toda a coletividade, tutela essa consistente num dever, e não somente em mera norma moral de conduta. E, ao referir-se à coletividade e ao Poder Público, leva-nos a concluir que a proteção dos valores ambientais estrutura tanto a sociedade, do ponto de vista de suas instituições, quanto se adapta às regras mais tradicionais das organizações humanas, como as associações civis, os partidos políticos e os sindicatos (Fiorillo, 2013, n. p.).

Para Celso Antônio Pacheco Fiorillo (2013), a CRFB/88 além de estabelecer que o direito ao meio ambiente ecologicamente equilibrado diz respeito à existência de um bem de uso comum do povo e essencial à sadia qualidade de vida (criando em nosso ordenamento o bem ambiental), ainda estabelece outras três concepções fundamentais: de que todos têm direito ao meio ambiente ecologicamente equilibrado; de que a CRFB/88 determina tanto ao Poder Público como à coletividade o dever de defender o bem ambiental, assim como o dever de preservá-lo; e de que a defesa e a preservação do bem ambiental estão vinculadas não só às presentes como também às futuras gerações.

Em complemento a esta ideia, Luís Paulo Sirvinskas acrescenta que o conceito jurídico de bem ambiental abrange todos os recursos naturais essenciais à sadia qualidade de vida, cuidando-se do denominado "bem de uso comum do povo", o qual transcende o bem pertencente ao particular ou ao Poder Público. Por esta razão, o bem ambiental não pode ser classificado como bem público, nem como bem privado, tendo em vista que se trata de uma terceira categoria. Todavia, tal bem se situa numa faixa intermediária entre o bem público e o bem privado, denominando-se bem difuso, pertencendo a cada um e, ao mesmo tempo, a todos (Sirvinskas, 2018).

Face o exposto, em razão de sua importância, as condutas e atividades lesivas ao meio ambiente (crime ambiental), mais especificamente o desmatamento ilegal, deve ser combatida pelo Estado e pela coletividade. Assim, em reforço a esta proteção, o poder legislativo infraconstitucional editou a então vigente lei no 9.605 , de 12 de fevereiro de 1998, dispondo sobre as sanções penais (perante o Poder Judiciário) e administrativas (perante a Administração Pública) derivadas de condutas e atividades lesivas ao meio ambiente. Menciono diploma normativo é conhecido popularmente como "lei de crimes ambientais" 
e tipifica as espécies de crimes contra o meio ambiente.

Uma das formas de desvendar a prática de crimes ambientais, está na utilização das perícias. De acordo com Marileia Ieno Gonçalves (2010), pode-se definir como perícia como uma expressão genérica que abriga diversos tipos de exames de natureza especializada, visando esclarecer determinados fatos sob a ótica científica. Logo, quando o conhecimento jurídico do magistrado não é suficiente para emitir opinião técnica, faz-se necessário lançar mão da instauração de perícia para apurar circunstâncias e/ou causas relativas a fatos reais, com vista ao seu esclarecimento. Em complemento, Romão, Alberto Trauczynski (2013), certifica que os procedimentos periciais resultarão na confecção do laudo pericial, o qual constará o parecer do perito acerca do que foi examinado:

Os procedimentos periciais constituem-se, grosso modo, de apurado exame de local com obtenção de registros fotográficos, elaboração de esquemas, croquis ou mapas, coleta de vestígios, processamento dos vestígios, exames laboratoriais e posterior confecção do Laudo Pericial (Trauczynski, 2013, p. 31).

De forma sucinta, laudo pericial pode ser definido como o resultado da perícia apresentado em um documento contendo conclusões fundamentadas, apontando fatos, circunstâncias, princípios e pareceres objetivos sobre a matéria examinada. Ainda, será composto por respostas aos quesitos, que são perguntas relacionadas aos fatos formulados ao perito, que constituem justamente o objeto da perícia (Mazzarotto, 2020).

Levando em consideração que a confecção do laudo pericial requer que seja realizado por profissional capacitado, a perícia judicial pode ser ordenada pelo magistrado ou requerida por quaisquer uma das partes envolvidas no processo, desde que com aval daquele.

Grosso modo, a perícia judicial, como o próprio nome sugere, é aquela solicitada pelo juiz, ou solicitada pelos demais envolvidos no processo em análise. Ela é necessária para conferência de dados, verificação de provas apresentadas pelos envolvidos no processo ou, ainda, coletar provas. Tudo isso estará registrado no laudo pericial confeccionado pelo profissional competente (Ribaski, 2021).

A perícia judicial é designada a um perito escolhido pelo magistrado e que não tenha relação com nenhuma das partes envolvidas no processo. A solicitação chegará ao perito com quesitos, ou seja, perguntas feitas pelo juiz que devem ser respondidas após a análise técnica dos documentos. O perito terá um prazo para executar o serviço e as partes podem indicar assistentes técnicos para acompanhar. A imparcialidade, o sigilo e a exatidão das informações devem ser seguidas à risca pelo perito. Ao solicitar a perícia judicial, geralmente a discussão se centra em questões de valores (Ribaski, 2021, p. 2).

O termo perícia judicial define quaisquer tipos de perícias ordenadas pelo magistrado ou requeridas pelos demais envolvidos. Entre as variadas perícias que podem surgir a necessidade no decorrer dos processos judiciais, tem-se a perícia ambiental. A seu respeito, Lilian Alves de Araújo esclarece que:

A Perícia Ambiental é um meio de prova utilizado nos processos judiciais, sujeita à regulamentação prevista pelo Código de Processo Civil, com prática forense comum às demais modalidades de perícia, mas que irá atender a demandas específicas advindas das questões ambientais (Araujo, 2008, p. 108).

Conforme sobredito, a perícia ambiental surge normalmente em decorrência de uma demanda processual e tem como objeto de estudo o meio ambiente nos seus aspectos abióticos, bióticos e socioeconômicos, correlacionando a natureza com as atividades humanas. Desta feita, a perícia ambiental é um meio de prova utilizado em processos judiciais para determinar a extensão do dano ambiental e estimar a indenização a ser devida (Gonçalves, 2010). 
A Perícia Ambiental tem como objetivo determinar a causa, a origem do Dano, Impacto e/ou Passivo Ambiental, se o mesmo foi ou não ato criminoso, se há risco à vida (como um todo/dentro do princípio de sustentabilidade), se houve falhas no sistema de proteção e operação do(s) Objeto(s) periciado(s). Dessa forma, o Laudo Pericial é uma modalidade de Auditoria Ambiental, tornando-se um instrumento de vigilância e regulamentação do contexto da Gestão Ambiental (Gonçalves, 2010, p. 10).

As provas periciais estão regulamentadas no Código de Processo Civil, lei nº 13.105, de 16 de março de 2015, notadamente na Seção X do Capítulo XII do Título I da Parte Especial. Assim, em reforço ao já exposto, Marcelo Schmid certifica que a perícia ambiental também tem como objetivos: auxiliar o juiz no entendimento de conhecimentos técnicos na área ambiental e do correto entendimento da vasta e complexa legislação ambiental brasileira, em âmbito federal, estadual e municipal; e em médio à complexidade do assunto, prover ao juízo uma interpretação dos fatos do processo que se relacionam à matéria ambiental, de modo a defender da melhor forma possível o conteúdo da legislação ambiental, de forma técnica e imparcial (Schmid, 2020).

A evolução da ciência pericial acarreta novos horizontes para a solução de crimes ambientais e auxilia no convencimento das autoridades envolvidas na persecução criminal: política, Ministério Público, e Poder Judiciário. Doutra banda, para se esquivar da penalização, a criminalidade em desfavor do meio ambiente também se sofistica e, por consequência, aplicam novas metodologias para a prática de crimes ambientais, adotadas com a finalidade de diminuir ou mascarar os vestígios de uma conduta delitiva, impulsionando a criminalística a um processo evolutivo (Trauczynski, 2013). Logo, a persecução dos crimes ambientais necessita de evolução e, sobretudo, estratégia de campo de atuação, em especial, na região da Amazônia Legal, que apresenta os elevados índices de crimes ambientais.

De acordo com os dados constante no Relatório Executivo "Justice and socio-environmental protection in the Brasilian Amazonia", apresentado no "I Webinário Internacional Brasil-União Europeia: Justiça e Políticas de Proteção Socioambiental" e idealizado pelo Conselho Nacional de Justiça [CNJ], do ano de 1986 a 2020 foram registradas, na região amazônica, aproximadamente 88.566 ações judiciais com matéria de crimes ambientais. Desse montante: 24.171 foram casos envolvendo casos de danos ambientais; 16.073 foram crimes contra a flora; 11.208 foram pedidos de revogação ou cancelamento de multas; 23 foram casos de manejo de floresta pública/dano ambiental; 807 foram casos de preservação de recursos naturais (BRASIL, 2020, p. 83). Todos esses processos estão distribuídos entre os tribunais que possuem jurisdição nos Estados relacionados à Amazônia Legal (Acre, Amapá, Amazonas, Mato Grosso, Rondônia, Roraima, Tocantins, Pará e do Maranhão na sua porção a oeste do Meridiano $44^{\circ}$ ), conforme pode ser verificado no quadro abaixo:

Quadro 1. Número de processos judiciais com matéria ambiental tramitados nos Tribunais com jurisdição na Amazônia Legal (1986-2020).

\begin{tabular}{|l|r|}
\hline \multicolumn{1}{|c|}{ Tribunal } & Total de processos judiciais com matéria ambiental por Tribunal \\
\hline TRF1 & 34,615 \\
\hline TJPA & 19,651 \\
\hline TJMT & 12,034 \\
\hline TJRO & 6,101 \\
\hline STJ & 5,458 \\
\hline TJAM & 4,534 \\
\hline TJMA & 2,643 \\
\hline TJAP & 1,376 \\
\hline TJRR & 1,136 \\
\hline TJTO & 937 \\
\hline TJAC & 81 \\
\hline Total & $\mathbf{8 8 , 5 6 6}$ \\
\hline
\end{tabular}

Fonte: Brasil, CNJ (2020, p. 86. Adaptado). 
De fato, a região que compõe a Amazônia Legal representa a área de maior foco de violação ao bem ambiental. Os crimes ambientais nesse campo observado são diversos. Por esta razão, a formação de profissionais capacitados para auxiliar os magistrados na elucidação dos fatos que ensejaram em crimes ambientais, é fundamental para a persecução desses crimes. Entre os profissionais capacitados para tanto, cita-se os peritos ambientais.

O gênero perito criminal, no qual comporta a espécie peritos ambientais, são profissionais especializados em produzir conhecimento técnico-científico para a construção de uma verdade, e havendo por finalidade dar suporte ao Poder Judiciário na elucidação e definição de crimes no que concerne sua autoria e materialidade (Medeiros, 2020).

A atividade pericial desenvolvida pelo perito ambiental terá por finalidade apresentar três elementos necessários no laudo pericial, quais sejam: dano - caracterizado pelo prejuízo, perda da qualidade, deterioração, ruína ou estrago ambiental; atividade lesiva - compreendendo qualquer atividade que causa danos, ainda que potenciais; e nexo causal - indicador de fatos/atividades que causam danos (Almeida, 2006).

De modo geral, os principais procedimentos que compõem a metodologia de perícia (ambiental) são os seguintes: leitura completa e criteriosa dos autos do processo; levantamento preliminar (casos semelhantes; legislação); vistoria do local; e laudo (pericial), contendo o relatório de vistoria e o parecer conclusivo) (Mazzarotto, 2020).

Uma vez realizado a leitura completa e criteriosa dos autos do processo, bem como o levantamento preliminar, a perícia segue com a identificação da área em que ocorreu (ou ocorre) o fato que consta nos autos do processo. Realizado a identificação da área, é feito, por conseguinte, a vistoria no local para identificar o dano, com a descrição das atividades ou intervenções realizadas (construção, reforma, ampliação, instalações de obras ou serviço, supressão de vegetais e lançamento de despejo, tais como: esgoto, produtos químicos, lixo, entre outros), e esclarecendo acerca da identidade do potencial poluidor (Mazzarotto, 2020).

Deve-se esclarecer e registrar as datas em que ocorreram as intervenções e as alterações produzidas nas características do meio ambiente, além de consequências observáveis em termos de saúde, segurança e bem-estar da população. Também deve ser informado se as intervenções geraram condições desfavoráveis a atividades sociais e econômicas; se afetaram a biota, as condições estéticas ou sanitárias, ou se lançaram ao ambiente matérias em desacordo com os padrões ambientais legais (Mazzarotto, 2020, p. 94).

Além da identificação do dano e da atividade lesiva, a vistoria no local servirá para elucidar o nexo causal, que é a constatação de relação efetiva entre causa e efeito, isto é, a comprovação de que o dano efetivo foi decorrente de ação voluntária, negligente ou imprudente. Concluso a vistoria no local, segue para o último procedimento da metodologia pericial: confecção do laudo pericial, registrando o relatório de vistoria e o parecer conclusivo (Mazzarotto, 2020).

No laudo pericial, o relatório de vistoria compreenderá na descrição detalhada, fundamentada e documentada de cada atividade que foi realizada pela perícia. Em seu turno, o parecer conclusivo deve responder aos requisitos ou questões que compõem a demanda, que será considerada pelo magistrado para a formular o embasamento da sentença (Mazzarotto, 2020). Assim, a perícia ambiental tem por propósito diversos, apresentando como principal deles a formação de provas para auxiliar o juiz na confecção da sentença.

Em sintonia ao exposto alhures, Marcelo Schmid (2020) sinaliza que a perícia ambiental apresenta os seguintes objetivos, conforme pode ser verificado no quadro abaixo: 
Quadro 1. Objetivos da Perícia Ambiental.

\begin{tabular}{|l|l|}
\hline OBJETIVOS & DESCRIÇÃO \\
\hline Ser um meio de produção de provas & $\begin{array}{l}\text { A perícia judicial, nesta incluindo a perícia ambiental, é um meio de } \\
\text { produção de provas previstos no Código de Processo Civil (lei no 13.105, } \\
\text { de } 16 \text { de março de 2015, na Seção X do Capítulo XII do Título I da Parte } \\
\text { Especial), que está disponível tanto para as partes litigantes quanto para o } \\
\text { magistrado para auxiliar na promoção da justiça. }\end{array}$ \\
\hline Prestar auxílio para o juiz & $\begin{array}{l}\text { A perícia ambiental auxilia o magistrado com um conhecimento } \\
\text { especializado que ele não possui, de modo a lhe dar condições objetivas } \\
\text { para que tome a melhor decisão possível. }\end{array}$ \\
\hline Solucionar demandas controversas & $\begin{array}{l}\text { No boje de um processo judicial tem-se duas partes litigantes, isto é, duas } \\
\text { pessoas naturais ou jurídicas, ou o Estado (Ministério Público, Defensoria } \\
\text { Pública etc.) versus as pessoas naturais ou jurídicas, cada qual defendendo } \\
\text { a sua versão sobre uma demanda controvertida, isto é, sobre um fato do } \\
\text { qual não há consentimento pelas partes. Logo, a opinaão técnica do perito é } \\
\text { de fundamental importância para esclarecer a demanda. }\end{array}$ \\
\hline Prover uma opinião imparcial & $\begin{array}{l}\text { O perito judicial, de modo geral, sempre estará comprometido com a } \\
\text { verdade e, de forma alguma, pode ter algum tipo de relação com quaisquer } \\
\text { das partes envolvidas no processo que possa comprometer a imparcialidade } \\
\text { de sua opinião. Assim, em um litígio entre duas partes com suas versões } \\
\text { parciais dos fatos, a perícia tem o papel importante de trazer uma terceira } \\
\text { opinião, desprovida de parcialidade e calcada em conhecimento técnico } \\
\text { especializado. }\end{array}$ \\
\hline
\end{tabular}

Fonte: Schmid (2020, p. 38-39. Adaptado).

A norma albergada no art. 149 do Código de Processo Civil (CPC) determina como auxiliares da Justiça, além de outros cujas atribuições sejam determinadas pelas normas de organização judiciária, o perito:

Art. 149. São auxiliares da Justiça, além de outros cujas atribuições sejam determinadas pelas normas de organização judiciária, o escrivão, o chefe de secretaria, o oficial de justiça, o perito, o depositário, o administrador, o intérprete, o tradutor, o mediador, o conciliador judicial, o partidor, o distribuidor, o contabilista e o regulador de avarias (Brasil, 2015).

O CPC determina no seu art. 156 que o juiz será assistido por perito quando a prova do fato depender de conhecimento técnico ou científico. A escolha do perito não se dar de modo aleatório. Segundo o CPC, os peritos serão nomeados entre os profissionais legalmente habilitados e os órgãos técnicos ou científicos devidamente inscritos em cadastro mantido pelo tribunal ao qual o juiz está vinculado. Para além disso, o perito tem o dever de cumprir o ofício no prazo que lhe designar o juiz, empregando toda sua diligência (Brasil, 2015). Cumpre ressaltar que o papel do perito ambiental pode ser exercido por uma série de profissionais que possuem, em sua formação acadêmica, prerrogativa para lidar com questões ambientais, como por exemplo: engenheiros ambientais; engenheiros florestais; biólogos; engenheiros químicos; entre outros (Schmid, 2020).

De acordo com Schmid (2020), as perícias ambientais abrangem toda a multidisciplinaridade da matéria, embora alguns temas sejam mais comuns, como os exemplos do quadro abaixo. 
Quadro 2. Temas mais comuns que exigem a intervenção de um perito ambiental.

\begin{tabular}{|c|c|}
\hline $\begin{array}{l}\text { Área de } \text { Preservação } \\
\text { (APP) }\end{array}$ & $\begin{array}{l}\text { A interpretação da aplicação do conceito de Área de Preservação } \\
\text { Permanente, disposto no Código Florestal (lei no } 12.605 / 2012) \text {, gera uma } \\
\text { série de controvérsias, vez que este diploma normativo possui lacunas } \\
\text { que dão margem a interpretações diversas e até mesmo conflitos de } \\
\text { competência legislativa e administrativa. As perícias ambientais são } \\
\text { igualmente necessárias em meio urbano, em que há dúvida quanto à } \\
\text { tratativa adequada do tema gera uma série de consequências de grande } \\
\text { impacto econômico para a sociedade, como a título de exemplificação, } \\
\text { sentenças judiciais que determinam a demolição de construções } \\
\text { supostamente localizada em APP. }\end{array}$ \\
\hline Supressão de vegetação & $\begin{array}{l}\text { O corte (supressão) de vegetação no território brasileiro, segundo prevê o } \\
\text { Código Florestal, deve ser antecedido por autorização pelo órgão } \\
\text { ambiental competente. De forma análoga à APP supracitada, essa } \\
\text { questão também gera uma série de dúvidas que demanda a avaliação } \\
\text { técnica da vegetação a ser suprimida, avaliação essa que precisa ser } \\
\text { realizada por um perito ambiental. }\end{array}$ \\
\hline $\begin{array}{l}\text { Avaliação de passivos ambientais } \\
\text { decorrentes de contaminação por uso } \\
\text { industrial }\end{array}$ & $\begin{array}{l}\text { Durante o processo de fusão e/ou aquisição de empresas, é normal a } \\
\text { identificação de passivos ambientais decorrentes de contaminação de } \\
\text { terrenos industriais. Muitas das vezes, o custo para a remediação } \\
\text { ambiental dessa área se torna mais caro que seu próprio valor } \\
\text { imobiliário, logo, uma correta avaliação do passivo ambiental é } \\
\text { absolutamente necessária e objeto da perícia judicial. }\end{array}$ \\
\hline Avaliação de danos ambientais & $\begin{array}{l}\text { Os danos causados à uma floresta nativa, ou até mesmo à uma cultura } \\
\text { agrícola, costuma figurar entre os temas demandados em perícias } \\
\text { ambientais. }\end{array}$ \\
\hline $\begin{array}{l}\text { Determinação de limites e localização } \\
\text { de áreas }\end{array}$ & $\begin{array}{l}\text { Levando em consideração à extensão territorial do Brasil, é normal a } \\
\text { existência de sobreposições entre áreas privadas ou de áreas privadas } \\
\text { com unidades de conservação ou terras indígenas, demandando a } \\
\text { necessidade de realizar perícia técnica para a determinação dos limites } \\
\text { corretos, especificamente um perito de geoprocessamento. }\end{array}$ \\
\hline
\end{tabular}

Fonte: Schmid (2020, p. 40. Adaptado).

Embora não seja o objeto de discussão do presente escrito, cumpre salientar que a intervenção da perícia ambiental também pode ser utilizada antes mesmo da ocorrência de um litígio, de modo preventivo ou indicativo de possíveis impactos ambientais que serão experimentados após a atividade humana causadora do impacto. A Resolução $\mathrm{n}^{\circ} 1$, de 23 de janeiro de 1986 do Conselho Nacional do Meio Ambiente [CONAMA] define o que venha ser impacto ambiental:

Art. $1^{\circ}$ Para efeito desta Resolução, considera-se impacto ambiental qualquer alteração das propriedades físicas, químicas e biológicas do meio ambiente, causada por qualquer forma de matéria ou energia resultante das atividades humanas que, direta ou indiretamente, afetam:

I - a saúde, a segurança e o bem-estar da população;

II - as atividades sociais e econômicas;

III - a biota;

IV - as condições estéticas e sanitárias do meio ambiente;

$\mathrm{V}$ - a qualidade dos recursos ambientais (Brasil, 1986).

A Resolução $n^{\circ}$ 1/1986 do CONAMA determina que o licenciamento de certas atividades modificadoras do meio ambiente dependerá de elaboração de Estudo de Impacto Ambiental (EIA) e respectivo Relatório de Impacto Ambiental (RIMA), a serem submetidos à aprovação do órgão estadual competente. Entre as atividades que necessitam do EIA e do RIMA, tem-se a construção de usinas de geração de eletricidade, qualquer que seja a fonte de energia primária, acima de 10 MW; a exploração econômica de madeira ou de lenha, em áreas acima de 100 hectares ou menores, quando atingir áreas significativas em termos percentuais ou de importância do ponto de vista ambiental; projetos urbanísticos, acima de 100 ha ou em áreas consideradas de relevante interesse ambiental; e projetos Agropecuários que contemplem áreas acima de 1.000 ha ou menores, neste caso, quando se tratar de áreas significativas em termos percentuais ou de importância do ponto de vista ambiental, inclusive nas áreas de proteção ambiental (Brasil, 1986). 
A elaboração do EIA e do RIMA é realizada por peritos ambientais. Desta feita, a legislação busca atenuar a ocorrência de impactos ambientais decorrentes de atividades humanas potencialmente lesiva ao meio ambiente. Entretanto, na hipótese de o licenciamento da atividade modificadora do meio ambiente for aprovado e perceber que, no caso concreto, os impactos ambientais exorbitam aos previstos no EIA e no RIMA, é possível que o Poder Judiciário possa ser invocado para apreciar os impactos ambientais a maior, bem como os crimes ambientais que foram cometidos. Para tanto, o magistrado precisará de um perito ambiental para realizar um novo EIA e RIMA da situação atual e realizar um comparativo com o apresentado no momento do processo de licenciamento da atividade modificadora do meio ambiente.

No âmbito do Poder Judiciário, os resultados a serem alcançados com a perícia ambiental requer a definição de quesitos de forma prévia, ou seja, o perito será guiado por quesitos que necessitam ser respondidos ao final de sua atividade pericial (laudo pericial). Levando em consideração que a intervenção do perito objetiva a busca real dos fatos em análise pelo magistrado, a norma disposta no art. 465 do CPC assegura que quaisquer das partes envolvidas no processo poderá apresentar requisitos a serem respondidos pelo perito.

Art. 465. O juiz nomeará perito especializado no objeto da perícia e fixará de imediato o prazo para a entrega do laudo.

$\S 1^{\circ}$ Incumbe às partes, dentro de 15 (quinze) dias contados da intimação do despacho de nomeação do perito:

I - arguir o impedimento ou a suspeição do perito, se for o caso;

II - indicar assistente técnico;

III - apresentar quesitos (Brasil, 2015).

Uma vez apresentando os quesitos por todas as partes, o magistrado irá avaliá-los, podendo indeferir os quesitos que julga impertinentes e, ainda, também formular os quesitos que entender necessário. Assim determina a norma disposta no art. 470 do CPC:

470. Incumbe ao juiz:

I - indeferir quesitos impertinentes;

II - formular os quesitos que entender necessários ao esclarecimento da causa (Brasil, 2015).

Os quesitos podem se apresentar na forma de perguntas diretas ou indiretas, objetivando orientar tecnicamente o trabalho do perito (SCHIMID, 2020, p. 45). Ou seja, os quesitos periciais representam o meio de que as partes ou o juiz podem, de certa forma, tentar direcionar o resultado da perícia, sem, contudo, influenciar na constatação do perito técnico. Esse direcionamento representa, na verdade, uma forma de realizar questionamentos e o papel do perito, ao responder aos quesitos, poderá apresentar elementos comprobatórios que corroborem a tese da parte que alega. Isso porque, por mais que o perito realiza um trabalho técnico de maneira imparcial, é por meio dos quesitos que esse profissional tem um balizamento do que as partes pretendem demostrar ou ser esclarecido ao juiz quando formulado por este último (Alvarenga, 2020).

Wishilen Thierry Rayzel Alvarenga (2020) chama a atenção quanto à estrutura dos quesitos periciais. Primeiro diz respeito à linguagem a ser observada: precisam ser elaborados em linguagem compreensível (simples e objetiva), visto que, de modo contrário, a difícil compreensão dos quesitos poderá impedir o seu objetivo inicial de receber respostas de maneira clara. Segundo, tem-se a necessidade de observar a estrutura lógica de apresentação dos quesitos: vigiar pela ordem cronológica dos fatos e situações, contribuindo para que os argumentos sejam mais bem explorados e explicitados durante a elaboração do laudo pericial. E terceiro, não se recomenda a formulação de quesitos genéricos, vez que poderá receber qualquer tipo de respostas: sempre que possível, os quesitos devem ser específicos em relação à situação em análise, com intuito de que possam expressar com detalhes todos os elementos necessários para auxiliar no convencimento do magistrado.

Diante da importância da atividade pericial, que ao final será entregue como resultado o laudo pericial, a norma albergada no art. 473 do CPC determina os elementos necessários que devem conter no laudo pericial, conforme pode ser 
verificado no quadro abaixo.

Quadro 3. Elementos constitutivos do laudo pericial (art. 473 do CPC).

\begin{tabular}{|l|l|}
\hline A exposição do objeto da perícia. & Art. 473, inciso I, do CPC \\
\hline A análise técnica ou científica realizada pelo perito. & Art. 473, inciso II, do CPC \\
\hline $\begin{array}{l}\text { A indicação do método utilizado, esclarecendo-o e demonstrando ser } \\
\text { predominantemente aceito pelos especialistas da área do conhecimento da } \\
\text { qual se originou. }\end{array}$ & Art. 473, inciso III, do CPC \\
\hline $\begin{array}{l}\text { Resposta conclusiva a todos os quesitos apresentados pelo juiz, pelas partes } \\
\text { e pelo órgão do Ministério Público. }\end{array}$ & Art. 473, inciso IV, do CPC \\
\hline
\end{tabular}

Fonte: Brasil (2015).

Nota-se que as normas albergadas no CPC direcionam o perito para a formulação de um laudo pericial com elementos mínimos que devem ser observados. Assim como na estruturação dos quesitos periciais, Schmid (2020) sinaliza que o laudo pericial também deve obedecer a algumas características fundamentais, quais sejam: organização e estrutura; clareza; e objetividade. Em relação à organização e estrutura, o laudo pericial deve dispor de suas informações de maneira organizada, para se fazer o mais didático possível e claro possível. Assim, recomenda-se que o documento possua uma estrutura muito bem definida, de modo a apresentar todos os elementos do objeto da discussão processual, para então adentrar nas respostas aos quesitos que serão respondidos.

No tocante à clareza, o perito poderá se valer de toda ferramenta de apoio que auxilie o profissional a tornar o laudo pericial mais claro e didático (poderá instruir o laudo pericial com planilhas, mapas, plantas, desenhos, fotografias ou demais elementos que julgar necessários). Já em relação à objetividade, o laudo pericial deve ser objetivo e se limitar à matéria que está discutindo no bojo do processo, ou seja, evitar a composição de informações excessivas e desnecessárias nas respostas dos quesitos (Schmid, 2020).

Em complemento, Josimar Ribeiro de Almeida (2006) tece considerações importantes acerca da estrutura do laudo pericial:

Deve ser evitada a reprodução quase literal das questões (quesitos) levantadas na etapa inicial e na constatação, pois corre-se o risco de cair em dissertações prolixas, com assuntos irrelevantes para a perícia. O laudo (pericial) deve ser inteligível, elaborado com clareza, abrangente e em estilo simples. Não deve conter omissões ou apresentar obscuridade. Refutam-se termos essencialmente técnicos, onde seu entendimento acarreta novas abordagens, resultando, mais uma vez, na indesejável prolixidade. Devemos lembrar que o laudo (pericial) se destina, em última análise, à leitura de juízes e advogados, desconhecedores da matéria da perícia (Almeida, 2006, p. 41).

Face o exposto, a perícia ambiental representa importante instrumento para solucionar os crimes ambientais apreciados pelo Poder Judiciário, sobretudo pelos Tribunais com jurisdição na região da Amazônia Legal, área de elevada incidência de violação ao meio ambiente. Embora não possível coletar informações no que diz respeito à quantidade de perícias ambientais que foram utilizadas na região da Amazônia Legal requeridas pelas partes dos processos ou ordenada pelos magistrados, dada a ausência dessas informações em fácies condições de consulta pelo cidadão de maneira geral, ainda assim é possível aduzir que a necessidade de intervenção do perito na região em análise é elevada. Isso porque conforme exposto alhures, entre os anos de 1986 e 2020, foram tramitados 88,566 processos judiciais com matéria ambiental perante os Tribunais com jurisdição na Amazônia Legal.

Diante do elevado número de processos que tramitam na Amazônia Legal, esses dados estatísticos servem de alerta para o combate aos crimes ambientais que ocorre nessa região, assim como a necessidade de formação técnica de mais peritos ambientais para atender a demanda do Poder Judiciário. Portanto, a cooperação entre o governo federal e os governos estaduais; instituições de ensinos superior; e institutos de perícias federais e estaduais é significativa para ajudar no processo de 
formação de mais peritos ambientais, que exercem papel de agente fundamental na solução de crimes ambientais pelo poder judiciário na Amazônia Legal.

\section{Conclusão}

O combate ao desmatamento ilegal ocorre antes, durante e após a prática criminosa. Embora a atuação do Poder Judiciário poderá ocorrer em qualquer uma das fases retro, é mais comum sua apreciação após a prática dos crimes ambientais. Para ocorrer uma repressão de forma satisfativa ao caso concreto, mediante a prolação da sentença, é necessário que os fatos sejam elucidados de modo que não pairam dúvidas para o magistrado em relação à dinâmica do fato criminoso.

Para tanto, a utilização da perícia ambiental é fundamental para sanar dúvidas e esclarecimentos técnicos dos quais o juiz não possui formação acadêmica para se chegar às respostas por conta própria. Por esta razão, o Código de Processo Civil prevê de forma expressa a figura do perigo como um agente auxiliador da Justiça.

A atuação do perito terá por resultado a entrega de um laudo pericial contendo as respostas de todos os quesitos periciais formulados pelas partes envolvidas no processo e até mesmo pelo juiz, documento este que comporá o bojo do processo e auxiliara o juiz na fundamentação da sentença. Entretanto, a confecção do laudo pericial deve der feita de maneira organizada e bem estruturada clareza na disposição das informações e objetividade nas respostas. Diante disso, o perito tem papel importante para elucidação dos crimes ambientais, objetos de apreciação pelo Poder Judiciário.

O número alarmante de desmatamento ilegal na Floresta Amazônica e o consequente elevado número de processos que tramitam nos Tribunais com jurisdição na Amazônia Legal com matéria ambiental sinaliza a necessidade de formação e/ou capacitação de peritos para atuarem nessa região e atender a demanda do Poder Judiciário nessa localidade. De todo o exposto, fica evidente que a solução de crimes ambientais pelo Poder Judiciário na Amazônia Legal depende, em parcela significativa dos casos, da utilização da perícia ambiental.

Recomenda-se que os trabalhos acerca da temática como a perícia ambiental também vêm sendo adotada nos procedimentos administrativos para a solução de crimes ambientais na Amazônia Legal, em especial às instituições e/ou órgãos governamentais que possuem como atividade fim a fiscalização e autuação de prática de crimes ambientais da Amazônia Legal. A utilização da perícia ambiental não é recurso que se limita ao Poder Judiciário. Logo, conhecer a aplicação da perícia ambiental no âmbito Administrativo para subsidiar a Administração Pública na lavratura de autos de infrações, bem como o índice de utilização, poderá robustecer a base de dados acerca da persecução dos crimes ambientais na Amazônia Legal, seja no âmbito Administrativo, seja no âmbito Judicial.

\section{Referências}

Almeida, J. R. (2006). Perícia ambiental, judicial e securitária: impacto, dano e passivo ambiental. Thex.

Alvarenga, W. T. R. (2020). Perícia judicial: aspectos legais e qualificação. Contentus.

Araújo, L. A. Perícia Ambiental. (2008). In: A questão ambiental: diferentes abordagens. Organização: Sandra Batista Cunha e Antônio José Teixeira Guerra. (4a ed.). Bertrand Brasil.

Brasil. (2020). Conselho Nacional de Justiça [CNJ]. Justice and socio-environmental protection in the Brasilian Amazonia. União Europeia. Brasília: CNJ. Recuperado de https://www.cnj.jus.br/wp-content/uploads/2020/11/JUSTICE-AND-SOCIO-ENVIRONMENTAL-PROTECTION-IN-THE-BRASILIANAMAZONIA_V-6_2020-12-16.pdf.

Brasil. Conselho Nacional do Meio Ambiente [CONAMA]. Resolução CONAMA nº 1, de 23 de janeiro de 1986 . Dispõe sobre critérios básicos e diretrizes gerais para a avaliação de impacto ambiental. http://www.ima.al.gov.br/wizard/docs/RESOLU\%C3\%87\%C3\%8 3O\%20CONAMA\%20N\%C2\%BA001.1986.pdf.

Constituição da República Federativa do Brasil de 1988. http://www.planalto.gov.br/ccivil_03/constituicao/constituicao.htm.

Fiorillo, C. A. P. (2013). Curso de direito ambiental brasileiro (14a ed.), Saraiva. 
Research, Society and Development, v. 11, n. 2, e30311225859, 2022

(CC BY 4.0) | ISSN 2525-3409 | DOI: http://dx.doi.org/10.33448/rsd-v11i2.25859

Gonçalves M. I. O que é perícia ambiental? (2010). Naturale: água gota preciosa. (4). https://www.diagrarte.com.br/wp-content/uploads/2014/12/naturale-4ed.pdf.

Instituto do Homem e Meio Ambiente da Amazônia [Imazon]. 2021. Desmatamento na Amazônia cresce 30\% em 2020 e bate recorde dos últimos dez anos. Recuperado de https://imazon.org.br/imprensa/desmatamento-na-amazonia-cresce-30-em-um-2020-e-bate-recorde-dos-ultimos-dez-anos/.

Lei $n^{\circ}$ 6.938, de 31 de agosto de 1981. Dispõe sobre a Política Nacional do Meio Ambiente, seus fins e mecanismos de formulação e aplicação, e dá outras providências. Recuperado de http://www.planalto.gov.br/ccivil_03/leis/16938.htm.

Lei $n^{\circ}$ 13.105, de 16 de março de 2015. Código de Processo Civil. http://www.planalto.gov.br/ccivil_03/_ato2015-2018/2015/lei/113105.htm.

Lei complementar $n^{\circ}$ 124, de 3 de janeiro de 2007. Institui, na forma do art. 43 da Constituição Federal, a Superintendência do Desenvolvimento da Amazônia - SUDAM; estabelece sua composição, natureza jurídica, objetivos, área de competência e instrumentos de ação; dispõe sobre o Fundo de Desenvolvimento da Amazônia - FDA; altera a Medida Provisória no 2.157-5, de 24 de agosto de 2001; revoga a Lei Complementar no 67, de 13 de junho de 1991; e dá outras providências. Recuperado de http://www.planalto.gov.br/ccivil_03/leis/lcp/lcp124.htm.

Mazzarotto, A. S. (2020). Direito e legislação ambiental. Contentus.

Medeiros, F. (2020). Políticas de perícia criminal na garantia dos direitos humanos: relatório sobre a autonomia da Perícia Técnico-Científica no Brasil. São Paulo: Fundação Friedrich Ebert. Recuperado de http://library.fes.de/pdf-files/bueros/brasilien/16396-20200811.pdf.

Prodanov, C. C., \& Freitas, E. C. (2013). Metodologia do trabalho científico: métodos e técnicas da pesquisa e do trabalho acadêmico (2a ed.) Novo Hamburgo: Feevale.

Ribaski, N. G. (2021). Perícia e avaliação ambiental: um olhar pela legislação. Curitiba: Editora Reflexão Acadêmica.

Sirvinskas L. P. (2018). Manual de direito ambiental. (16a ed.), Saraiva Educação.

Schmid, M. (2020). Auditoria e perícia ambiental, Contentus.

Trauczynski, R. A. (2013). Perícias criminais em delitos contra a flora no estado de Santa Catarina: diagnóstico, metodologia e perspectivas (Dissertação de mestrado). Universidade Federal de Santa Catarina, Centro de Ciências Biológicas, Programa de Pós-Graduação Mestrado Profissional em Perícias Ambientais, Florianópolis, Santa Catarina. https://repositorio.ufsc.br/handle/123456789/107134. 